\title{
A recent history of the journal, 1980-2005
}

Bell (1980) gave a detailed history of the Journal up to 1979. A key event in the 1970s had been the closer ties with Cambridge University Press, who were willing and able to deal with the financial and legal aspects, distribution, advertising etc. It was at this stage that the detailed 'Instructions to Authors' were produced. Much of the amendment required to papers concerned the use and presentation of statistical analyses and many authors were given guidance on how to analyse that data they were trying to publish. It is likely that this attention to editing and help for authors was responsible for the increase in the number of papers received, being less than 200 per year in 1972, rising to 390 in 1985 and still over 300 in 1989.

Cambridge University Press assisted with the additional work involved with this by increasing the support given to the editorial board by first Mrs Wigley, then Miss Northeast, followed by Miss Jane King. These editorial assistants, then as now, had much to do with technical editing, checking all references, preparing copy for the printers, reading first proofs and noting any special questions before sending them to authors, checking the author's corrections and comments, making up each issue to the required number of pages, reading the second proofs before their final reading and, of course, answering all the printers' queries.

\section{TURBULENT YEARS (1988-1990)}

The Journal had, for a number of years, been edited by Professor J.W. L. Beament and $\mathrm{Mr}$ W. J. Ridgman, who resigned in 1987. Ridgman agreed to become the Book Review Editor, an innovation for the Journal. D. Walters, a statistician by training, was appointed as Senior Editor on 12 May 1988 and Sir Kenneth Blaxter took on the role of chairman of the Editorial Board. The executive editor was initially Miss J. King, followed by Mrs J. Cheney and Mrs S. Jellis.

The Blaxter/Walters team discussed the future of the journal and decided, with the approval of Cambridge University Press, to propose the transfer of the editorial office to the Department of Agriculture at the University of Nottingham. The details of the transfer were discussed at a meeting at Sutton Bonington on 20 April 1990 which was attended by Sir Kenneth Blaxter and Dr Walters (representing the editors), Dr Ziemcaki and Dr Maria Murphy (representing Cambridge University Press), Professor Keith Scott and the Senior Editor designate Prof Whittington (both from Nottingham).
The Journal continued to be edited from the Press Building for a further six months, and then removed to Sutton Bonington in January 1991.

\section{1-1998 (W. J. (DICK) WHITTINGTON)}

The first step was for Dick Whittington to advertise for an Executive Editor and Nancy Boston was appointed. She began work (as did Dick) in the first week of November 1990, and on 20 November they collected the filing cabinets from Cambridge. At this time and through December, they benefited very much from the assistance and advice given by Judith Cheney and Susan Jellis. Papers continued to pass from Cambridge to Sutton Bonington throughout November and December then from January 1991 they were on their own.

In 1998 the Journal went 'on-line' and in 1996 Cambridge University Press decided to increase the number of parts per volume from 3 to 4 . This increasingly centred attention on proof reading and preparation of the next issue.

A matter of continual interest was the number of papers submitted to the Journal. The annual figure had risen above 200 in 1973 and passed 300 in 1978. A decline had, however, started from 1985 (390 submissions) and continued erratically until, in 1998, the number was similar (159) to that in 1970 (156). Variation in the number of UK submissions might have been related to rationalization of teaching and research in certain universities (Cambridge, Leeds), the closure or reorganization of research stations (Babraham, Letcombe and the P.B.I. Cambridge) and also the foundation of new journals, e.g. Field Crop Research (1978) and the European Journal of Agronomy (1992). Factors increasing submissions were likely to be associated with the greater availability of research grants and non-UK postgraduate students, and increasing activity of staff members.

The causative factors described above were outside the control of either the Editors or Cambridge University Press but others were not. The Editors became aware that the time between the date of acceptance of a paper after final revision and its appearance in print had increased. At the same time, prospective authors were under increasing pressure to publish, not only to enhance their own chances of promotion but also to raise the reputation of their department, station or university in 'assessment' exercises. When the Editorial Board drew attention to the increasing delay, Cambridge University Press responded positively by allocating more pages per 
annum from 831 in 1991 to around 1000 through 1996-1998. However, the benefit of increasing the number of pages was considerably reduced by the increasing length of the papers submitted and accepted.

Dick Whittington analysed where Rothamsted staff published their papers. The concern was that when staff were encouraged to publish in journals with a high impact factor, this might exclude the Journal of Agricultural Science. Fortunately, it seemed the choice of journal was determined by the subject matter so that there was no obvious bias against the Journal. Nevertheless it was felt that there was a need to encourage papers on wider aspects (e.g. molecular biology) when the work was relevant to our interests.

In 1997, Dick Whittington discussed the 'succession' with Professor T. Lewis (then the Chairman of the Board of Editors), and consulted the Editorial Board. They felt that there was potential benefit in having two Senior Editors, responsible for different areas of agricultural science and who would be attending different conferences and meetings. This would widen the opportunity to encourage contributions or reviews to the Journal. Cambridge University Press agreed to this proposal. David Wilman (University of Wales, Aberystwyth) and Julian Wiseman (University of Nottingham) were appointed from the start of 1999. The Editorial Assistant Nancy Boston had been 8 years in the post, was widely known to authors and there had been many expressions of gratitude for her meticulous work on their submitted papers, and would remain at Sutton Bonington. Dr Wilman would have appropriate support in Aberystwyth. Technological advance permitted the two offices to have communication through e-mails, fax, the telephone and even by letter!

\section{9-2001 (WILMAN AND WISEMAN)}

For the three calendar years 1999-2001, the two Joint Senior Editors were Dr Julian Wiseman, Reader in Animal Production in the University of Nottingham, who took responsibility for the 'animal' content of the Journal and Dr David Wilman, Reader in Agricultural Science in the University of Wales, Aberystwyth, who took responsibility for the other aspects of agricultural science (crops and soils). Nancy Boston gave up her post of Executive Editor at the end of February 1999. The editorial work was then handled by the two Senior Editors, each with an Assistant, and by a copy editor, Lesley Bennun, who worked from her home, near Ely. David Wilman was assisted initially by Vicky Davies and subsequently by Rhysian Bowen and then Anne Roberts. Julian Wiseman was assisted initially by Mavis Secker and subsequently by Sheila Northover.

During 1999-2001, eight issues were published in each year. The average number of papers per issue was 11.5 and the average number of pages per paper was 9.7. Four of the 277 published papers were reviews. Eighty-one book reviews were published. Of the papers published, $55 \%$ were predominantly concerned with plants, $28 \%$ with animals, $14 \%$ with soils and/or fertilizers and $3 \%$ with research methods and/ or models. Of the papers published, $33 \%$ were from the UK, $22 \%$ from other parts of Europe, $22 \%$ from Asia, $9 \%$ from Australasia, $7 \%$ from Africa and 7\% from the Americas. The total number of papers received was 609 (i.e. 203 per year), compared with 618 in the previous 3-year period, 1996-98. The rejection rate was $44 \%$, compared with $47 \%$ in 1996-98. The number of subscriptions declined from 997 in 1990 to 682 in 1998 and 560 in 2001. These data sets were considered important in identifying trends and to inform the journal on policy decisions.

It was noted at the Editorial Board meeting in 2000 that the Journal was available on the Cambridge Journals Online site. Tables of contents and abstracts could be viewed online free of charge; full papers could be viewed by those institutions which also had a print subscription to the Journal; online-only subscriptions were to be introduced. An editorial was published in the August 1999 issue confirming the Journal's policy of publishing papers from all parts of the world in all aspects of agricultural science. It was noted that the editors wished to publish good papers with a minimum of delay, consistent with thorough refereeing. It was also noted that the Journal continued to have a wide circulation (in over 80 countries) and made no page charges.

The instructions to authors, the statistical note for authors, the notes on mathematical models and the notes on style and editorial conventions were all updated in 1999/2000. The updated instructions to authors were included in the January 2000 issue and those plus the statistical note and the notes on style were included in the May 2001 issue. A new cover design was used from January 2000 onwards.

It was agreed at the 2000 Editorial Board meeting that it was important to avoid unnecessary delay between the first submission of a paper and a response (accept, revise or reject) being sent to the author. At the 2001 Board meeting, it was reported that, for papers submitted in 2000 , the average time between submission and response was 6.5 weeks. Following consultation with Board members, it was decided to invite readers to write letters that would be considered for publication in the Journal. A note to this effect was included in the May 2001 issue. It was decided at the 2000 Board meeting to publish the names of referees (excluding any who wished to be excluded) as a public acknowledgement of their work. The first such list was published in the March 2002 issue, covering those who refereed papers that were published or rejected in 2001. 
The number of papers submitted to the Journal increased from 156 in 1970 to 390 in 1985, declined to 159 in 1998, recovered to 201 in 1999, 195 in 2000 and 213 in 2001 . These numbers were near optimum in relation to the editorial resources available and allowed the prompt publication of a sufficient number of papers in eight issues per year.

\section{TO DATE (WISEMAN \& NAYLOR)}

David Wilman retired as Senior Editor at the end of 2001 and Professor Robert (Bob) Naylor (University of Aberdeen) took over the role of Senior Editor with responsibility for crops and soils papers. The main Editorial Office was located at the University of Nottingham where Julian Wiseman continued as the Senior Editor for animal topics. Communication between the offices was good except for the software which was supposed to track submitted manuscripts through the editorial system. This software, which was becoming outdated, could not cope with the relocations and ceased to work effectively. It was decided with Cambridge University Press not just to update but to move to on-line submission for all papers. It was hoped this would increase submissions as well as streamline the manuscript tracking process. The ScholarOne system was selected and customized for use by the Journal. Some training was provided for the Senior Editors and for the Editorial Assistants, now Jeanette Webb at Nottingham and Alison Sage at Aberdeen. After a delay, the system eventually went live in July 2004. Preliminary views from authors, and prospective authors, are favourable and our submission rate does seem to have risen in the second half of 2004. Inevitably there were a few teething problems as all users became familiarized with the system, but all seems to be settling down. In January 2005 there are still a few papers from the 'paper-paper' era, submitted before July 2004, in the system.

\section{THE FUTURE}

It is worth commenting that all concerned with the Journal, whether as Editors or Referees, generally regard it as an honour to serve the Journal which has contributed so much to the advance of agricultural science throughout the world. We have reflected on this global reputation, and also on the increasing numbers of papers submitted from outside the UK, by seeking to widen the membership of the editorial Board. It must be admitted, though, that any journal bases its success on the willingness of authors to use it. Authors too do seem to regard the Journal as a validation of the quality of their work.

Long may this continue.

\section{REFERENCE}

Bell G. D. H. (1980). Historical record of the Journal of Agricultural Science from its establishment in 1905 to 1980. Journal of Agricultural Science, Cambridge 94, $1-30$.

The following have served the Journal of Agricultural Science during the past twenty-five years as Editors and International Consultants:
E. J. Allen
R. B. Austin
B. W. Bache
T. Barry
Sir James Beament
G. D. H. Bell
S. C. Bishop
Sir Kenneth Blaxter
A. D. Care
M. D. Casler
P. S. Cocks
G. W. Cooke
B. R. Cullis
J. A. Currie
P. Day
W. Day
J. Davis
R. N. Edmondson
S. Edwards
R. H. Ellis
J. L. Jinks
A. E. Johnston
T. Komiyama
R. N. B. Kay
R. A. Kempton
E. S. Kristensen
C. N. Law
T. Lewis
D. B. Lindsay
G. M. O. Maloiy
R. W. Matthewman
J. S. Macfarlane
G. F. J. Milford
J. L. Monteith
T. R. Morris
R. E. L. Naylor
J. B. Owen
M. Peaker
C. J. Pollock
D. A. Preece 